Western University

Scholarship@Western

Psychiatry Publications

Psychiatry Department

$7-2014$

\title{
Improving trainee psychiatrist's handover: standard setting and audit
}

arun gupta

Newcastle University

Ruth Bevan

Newcastle University

Akshya Vasudev

Western University, avasude2@uwo.ca

Follow this and additional works at: https://ir.lib.uwo.ca/psychiatrypub

Part of the Psychiatry and Psychology Commons

Citation of this paper:

gupta, arun; Bevan, Ruth; and Vasudev, Akshya, "Improving trainee psychiatrist's handover: standard setting and audit" (2014).

Psychiatry Publications. 31.

https://ir.lib.uwo.ca/psychiatrypub/31 


\title{
Improving trainee psychiatrist's handover: standard setting and audit
}

Arun Gupta

\author{
Cherry Knowle Hospital, NTW NHS Foundation Trust, Sunderland, UK \\ Ruth Bevan \\ Monkwearmouth Hospital, NTW NHS Foundation Trust, Sunderland, UK, \\ and
}

Akshya Vasudev

Geriatric Psychiatry and Medicine, Western University, London, Canada

\begin{abstract}
Purpose - The 2006 Post Graduate Medical Education Trust Board (PMETB) trainees' survey indicated inadequacies in handover procedures amongst medical and psychiatry trainees nationwide; and in 2007 a local psychiatry trainees' survey found inadequate handover procedures. The purpose of this paper is to show how to improve handover practice through standard setting and sequential audit. Design/methodology/approach - A Trust wide Standard Operating Procedure (SOP) for handover was developed. Trainees were audited on perception of handover experiences (2008, 2009 and 2010).

Findings - The audit revealed that the SOP was not consistently followed. Handing over "active problems" (AP) was perceived to occur frequently in 2008 (93.75 per cent), improved in 2009 (100 per cent for AP, 98 per cent for "problems which may arise", (PA)); however deteriorated in 2010 (93 per cent for AP, 69 per cent for PA). Trainee satisfaction rates with handover improved each year (57 per cent in 2008, 75 per cent in 2009, 87 per cent in 2010, $\mathrm{X}^{2}=3.7, \mathrm{df}=2, p=0.16$ ).

Practical implications - SOP development, subsequent audits and sharing of results improved handover practice. This has implications for training and patient safety. This project demonstrates a method of improving handover practices in a large mental health trust.

Originality/value - The work conducted is of interest to those working in psychiatry, not only from an education and training perspective, but also for clinical practice, in the UK as well as internationally.
\end{abstract}

Keywords Education, Training, Clinical governance, Audit, Psychiatry, Handover

Paper type Research paper

\section{Introduction}

The previous Post Graduate Medical Education Trust Board (PMETB), now part of the General Medical Council (GMC), published a national survey of medical trainees in 2006[1]. Amongst other findings, the PMETB recommended that all NHS trusts should

The authors would like to thank all the trainees who participated in this audit project, in particular the rota point-of-contacts and the representatives delegated responsibility for collecting results for individual rotas. The authors would also like to thank Dr Suresh Joseph and Dr Andrew Brittlebank for their help and support and NTW NHS Foundation Trust library staff for assisting with the review of literature.

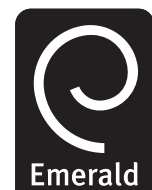

Clinical Governance: An International Journal 
CGIJ

19,2

84 have formalised, organised handover processes which includes a multi-professional model.

The term "handover" encompasses a broad range of communications within the health care system, occurring throughout a patient's journey during their contact with health services. The times we commonly recognise the significance of handover are: shift change, ward rounds, transfer of care and out of hours. The means of available communication between the interested parties influences the type of handover. Examples include: face to face meetings and telephone contact. Handover varies according to clinical setting.

Following the PMETB recommendations we conducted a baseline survey in 2007 investigating trainee psychiatrists' handover procedures and experiences in the Northumberland Tyne and Wear (NTW) NHS Foundation Trust, a large mental health trust in North East England employing over 6,000 staff serving a population of approximately 1.4 million and with inpatient units at six sites.

This survey indicated that current arrangements fell short of PMETB recommendations. We observed that broadly there were two handover systems, depending on the location of the clinical site. Firstly, where a shift system was in place, there was usually a face to face meeting at shift change. Secondly, where the on call system was non-resident, handover was conducted by telephone. Within both systems it appeared that handover was not standardised with no formal guidance to support or structure the process. Additionally there were wide variations in practise and attitudes with some survey comments suggesting that handover was considered non-mandatory and depended on perceived clinical risk. Many trainees were dissatisfied with the lack of clarity of handover processes. This suggested that current processes were inadequate and possibly unsafe. This is at variance with published research which highlights the need for a safe handover (Singh et al., 2007; Siemsen et al., 2012).

Acknowledging these findings, the authors devised a Trust wide Standard Operating Procedure (SOP) with the aim of improving trainees' handover practices, satisfaction and patient safety. Audits were conducted in three sequential years with a hypothesis that over the years there would be a positive change. The results of the audits were disseminated each year amongst trainees to improve the awareness of the $\mathrm{SOP}$, and promote adherence.

In the absence of prescribed targets for trainee handover from national regulatory agencies like the GMC, a study like this is needed to inform development of such national standards.

\section{Methods}

We describe here the methodology of improving and establishing the handover practices through the initial survey, development of the SOP and subsequent audits with dissemination of results. In 2007 all trainees working across the training sites of the Trust were contacted via their respective trainee representatives. Using a questionnaire developed individually for each site, baseline information about the current handover arrangements was gathered.

This survey showed that each site had its own method of non-formal handover arrangement. Trainees' feedback was that the handover processes did work, though partially. They acknowledged the need for a formal method of handover which needed to be specific for each site. Such a handover process would require considerations to be given to: the geographical area covered by a particular rota, whether the on call was 
resident or non-resident and if there was a possibility of face to face handover as opposed to via telephone.

Subsequently, a site specific SOP for formal handover procedures was developed in conjunction with the trainee representatives at each site (Figure 1). These SOPs were then submitted to the Trust board for approval, then to the Trust wide medical education committee for further dissemination. It was then issued to all existing doctors and new trainees at inductions from 2008 as part of their induction package. Following implementation of the SOP all trainees were asked to complete an annual questionnaire in 2008, 2009 and 2010 auditing handover practices, and adherence to the SOP. During this time the number of sites covered by the trainees increased from five to six due to trust reorganisation and expansion. We suspect this led to incomplete data acquisition in 2008 and 2009. After each round of data gathering the results were presented to the Trust medical education committee. Presentations were given at each site's training program in an effort to improve awareness about the importance of the handover processes, seeking feedback from trainees and staff and gathering suggestions for improvement of SOP if needed. The SOP and audit tool was refined each year based upon the feedback received.

\section{Statistical analysis}

Data were analysed using SPSS version 20.0 for Windows (SPSS Inc., Illinois). Demographic factors were summarised using frequencies and percentages for categorical variables. Chi-square analysis were used with a level of significance set at $p<0.05$.

\section{Results}

Table I shows audit questions and the results of three completed audit cycles for 2008, 2009 and 2010.

\section{Audit results}

The audit was conducted across four of the five (80 per cent) training sites within the Trust, with 32 out of 59 ( 54 per cent) responses. Data was extractable from 24 responses (41 per cent). The results revealed that mostly contact between on call doctors was made only when active issues required further input (94 per cent) but that handover was not routine (31 per cent). Further, the following concerns were raised; trainees arriving late for their shift ( 62.5 per cent), or not arriving (50 per cent), colleagues not answering their phones ( 25 per cent), trainees not being aware of who is on call (50 per cent) and not given adequate warning about delay in arrival of the on-call doctor (37.5 per cent).

Free text comments in the audit questionnaires suggested that a handover book, used at some sites to handover information or tasks, was not viewed as helpful. The comments also revealed occasions when the on call mobile phones had been left with medical secretaries resulting in possible gaps in cover. Despite limited awareness of the presence of a formal handover procedure the trainee statements revealed a consensus that a formal mandatory handover protocol needed to be adhered to ensure safe care.

\section{Trainee psychiatrist's handover}

85 
CGIJ

19,2

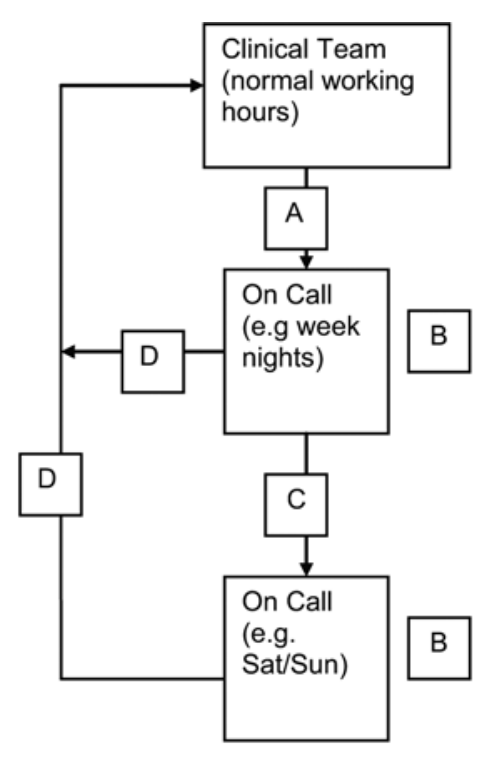

86

A The clinical team should inform the $1^{\text {st }}$ on call doctor of any issues that will, or are likely to, require their attention. Examples- pending admission, someone in seclusion, if a patient is unwell and may need input over the oncall period.

B At the start of the on call period the doctor must contact switchboard to confirm they are on call and check that their contact details are correct.

C Contact with the next on-call is mandatory (see note 1). Issues that should be discussed:

1. Active issues requiring interventions

2. Problems which may arise

3. Nothing to handover

D (Week day 9am) Handover any relevant issues to the appropriate clinical team by contacting the representing consultant's secretary (see note 2). For non- resident on calls information should be documented in the appropriate format (eg RIO entry) as soon as is practicable.

Note 1

Direct telephone contact is a minimum. Some sites have a face-face handover or handover of mobile or bleep.

The use of an on call diary is to provide additional information but does not replace the verbal handover.
Note 2

Time taken to handover after the on call shift is added to any compensatory rest taken.
Figure 1.

Summary of SOP 


\begin{tabular}{|c|c|c|c|c|c|c|c|}
\hline Questions & $\begin{array}{c}2008 \\
(n=24 / 59) \\
(\%)\end{array}$ & $\begin{array}{c}2009 \\
(n=56 / 58) \\
(\%)\end{array}$ & $\begin{array}{c}2010 \\
(n=55 / 64) \\
(\%)\end{array}$ & $\chi^{2}$ & df & $p$-value & $\begin{array}{r}\text { psychiatrist's } \\
\text { handover }\end{array}$ \\
\hline Sites/rotas covered & 4 & 5 & 6 & NA & NA & NA & \\
\hline $\begin{array}{l}\text { Do you routinely inform switch } \\
\text { board at the beginning of your on } \\
\text { call duty? }\end{array}$ & NA & 50 & 44 & 0.261 & 1 & 0.61 & 87 \\
\hline & NA & 68 & 69 & 0.004 & 1 & 0.95 & \\
\hline $\begin{array}{l}\text { Do you routinely make contact with } \\
\text { doctor you're handing over to? }\end{array}$ & 31.25 & 93 & 91 & 23.63 & 2 & $<0.001^{*}$ & \\
\hline What is discussed at handover? & & & & & & & \\
\hline Active problems & 93.75 & 100 & 93 & 0.152 & 2 & 0.93 & \\
\hline Problems which may arise & NA & 98 & 69 & 2.762 & 1 & 0.09 & \\
\hline Nothing to handover & 0 & 91 & 62 & 68.89 & 2 & 0 & \\
\hline $\begin{array}{l}\text { Is the handover you received } \\
\text { adequate? }\end{array}$ & NA & NA & 93 & NA & NA & NA & \\
\hline Is the handover you give adequate? & NA & NA & 98 & NA & NA & NA & \\
\hline \multicolumn{8}{|c|}{ Problems experienced around face-face handover: } \\
\hline Arriving late & 62.50 & 62.50 & 39 & 4.45 & 2 & 0.11 & \\
\hline Not arriving & 50 & 37.50 & 8 & 24.11 & 2 & $<0.001 *$ & \\
\hline Not answering phone & 25 & 25 & 0 & 23.33 & 2 & $0^{*}$ & \\
\hline Not knowing who is on call & 50 & 50 & 0 & 44.44 & 2 & $0 *$ & \\
\hline \multicolumn{8}{|l|}{ Are you provided with enough } \\
\hline Do you handover to the relevant & & & & & & & \\
\hline $\begin{array}{l}\text { period? } \\
\text { pamical tom on call }\end{array}$ & 0 & 84 & 77 & 68.72 & 2 & $0^{*}$ & \\
\hline \multicolumn{8}{|l|}{$\begin{array}{l}\text { During your normal clinical job do } \\
\text { you routinely handover items }\end{array}$} \\
\hline intervention? & NA & NA & 29 & NA & NA & NA & \\
\hline Do you receive adequate handover & & & & 018 & 1 & 068 & \\
\hline \multirow{3}{*}{$\begin{array}{l}\text { items requiring your intervention? } \\
\text { Are you aware of any incident when } \\
\text { a patient's care has been put at risk } \\
\text { because of inadequate handover? } \\
\text { Are you satisfied with the current } \\
\text { handover system? }\end{array}$} & NA & 75 & 82 & 0.18 & 1 & 0.68 & \\
\hline & NA & NA & 9 & NA & NA & NA & \multirow{3}{*}{$\begin{array}{r}\text { Table I. } \\
\text { Main finding of the audits } \\
\text { conducted in 2008, } 2009 \\
\text { and } 2010\end{array}$} \\
\hline & 57 & 75 & 87 & 3.7 & 2 & 0.16 & \\
\hline \multicolumn{7}{|c|}{ Notes: NA: Not asked; *Statistically significant at $p<0.05$} & \\
\hline
\end{tabular}

\section{Audit results}

This audit covered five out of six (83 per cent) sites and response rates were higher (56 out of 58 responses (97 per cent)). As expected, handover practices continued to vary depending on location and included face to face handover although most was conducted via telephone. The results suggest that handover had become a more established part of the on call routine, however, there remained a lack of knowledge about the SOP. Contact between on call doctors was much improved (100 per cent for active issues) and there 
CGIJ

19,2

88 were high rates for handing over problems which may arise (98 per cent) and contact when nothing required handing over (91 per cent). Nevertheless, trainee's experience of the handover they received from others was less good (only 68 per cent routinely made contact with the doctor they were handing over from) and gaps remained in communication between on call doctors and the usual clinical team responsible during normal working hours ( 25 per cent did not feel they received an adequate handover from the relevant clinical team). There remained a reliance on nursing staff to handover information on some of the sites. Worryingly, contact with switchboard to confirm which trainee was on call, and to confirm their preferred contact number was poor (50 per cent). This audit revealed continuing dissatisfaction with the handover system but the satisfaction rate was better (75 per cent in 2009 compared with 57 per cent in 2008). Some problems persisted including uncertainly about who was taking over the shift, difficulties in contacting trainees or trainees being late.

\section{Audit results}

Results were available from all six Trust sites (100 per cent). Responder rate was slightly lower (55 out of a total of 64 (86 per cent)). The results suggested a deterioration in the handover between on call doctors compared with 2009 (active issues: 93 per cent, problems which may arise: 69 per cent, nothing to hand over: 62 per cent). Handover from the usual clinical team to out of hours doctor was only 82 per cent. A new question relating to patient safety was added and this revealed that 9 per cent of trainees were aware of a risk incident arising due to inadequate handover. Overall trainee satisfaction with the handover system had improved (87 per cent). Fewer problems were reported relating to: doctors being late (39 per cent), difficulties in contacting the next on call ( 0 per cent) and doctors not arriving to take over shifts (8 per cent) (Figures 2 and 3 ).

\section{Discussion}

This project began following the 2006 PMETB survey which identified shortcomings in medical and psychiatry trainees' handover procedures nationally[1]. A Trust wide service evaluation, development of SOP, three sequential yearly audits and dissemination of results helped improve handover practices amongst trainees, although there is scope for further improvement.

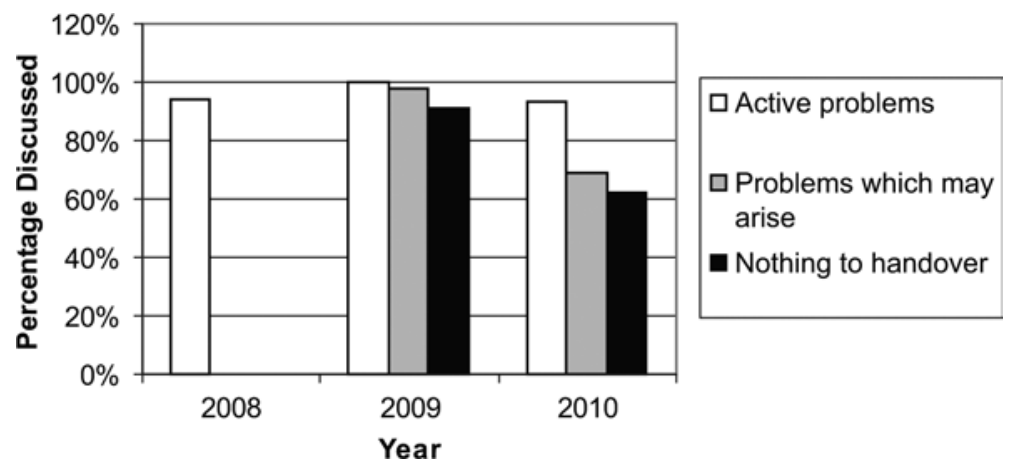

Figure 2.

Response to question: what is discussed at handover? 


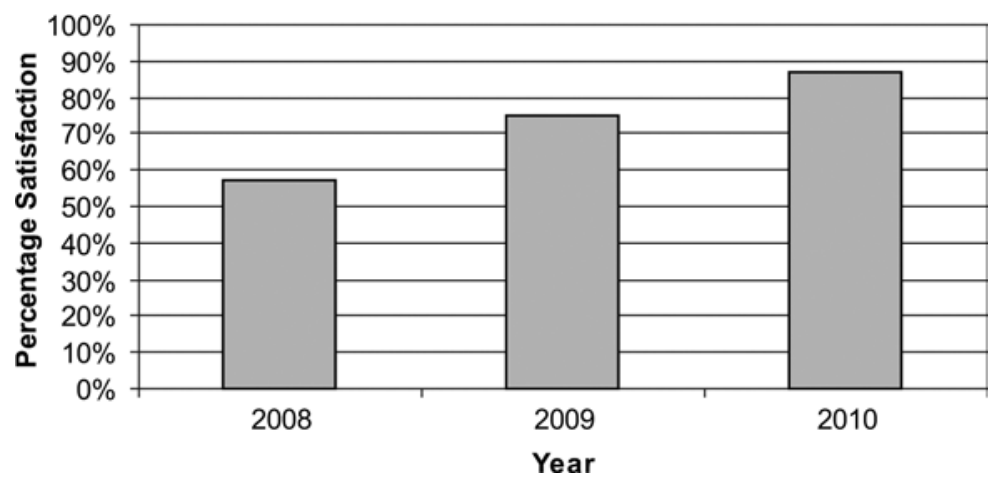

Trainee psychiatrist's handover

Figure 3.

Response to question: are you satisfied with the current handover system?

Various authorities have drawn attention to the issue of handover. The existing GMC[2, 3] and former PMETB[4] guidelines emphasise the importance of effective and organised handover arrangements involving clear communication to ensure continuity of patient care. The Royal College of Psychiatrists recognises that handover requirements are not confined to hospitals but also community teams[5]. The BMA Junior Doctor's Committee, in their guidance on clinical handover[6], discusses the implications of changing working patterns and the change from personal continuity, when the patients see the same doctor day after day, to system responsibility, which provides a team approach. It is suggested that handover practices are not only the responsibility of clinicians but also managers who must ensure that policies are in place and that they are monitored[2, 3, 5]. Leaders and managers must allow sufficient uninterrupted time for handover and provide access to supporting information systems[6]. "The Seven Steps to Patient Safety in Mental Health" issued by the National Patient Safety Agency (NPSA), highlights communication lapses within and between teams and agencies as linked to serious incidents[7]. It discusses good practise examples of improving interagency working and communication and relates this to an incident where essential safety information about a patient was not passed on.

Despite these agencies recognising the importance of handover processes there is currently no national framework or standards for a safe and effective handover that we are aware. This may be due to the diverse and differing practices and structures in place across the NHS and, perhaps, it would be unrealistic to think that one model could fit all. The NPSA is working to standardise handover arrangements in hospitals.

There are several studies published throughout the world related to the medical handover process. These studies cover a range of specialties however there are very few focusing specifically on psychiatry. All studies recognise the importance and complexity of the handover process and highlight the potential risks. Many acknowledge the time implications of an effective and comprehensive handover.

The introduction of the European Working Time Directive and changing shift patterns, introduces a phenomenon described by one paper as "a chain of Chinese whispers" (Cleland et al., 2009). Despite this, research suggests that shifts systems, as opposed to more traditional on call, are preferred by junior doctors due, in part, to a reduction in chronic tiredness (Nasmyth et al., 1991). This study also found that a formal handover resulted in more informed decision making by doctors. A study conducted within an Otolaryngology department in Bristol compared verbal handover 
CGIJ

19,2

90 with that supported by note taking and a printed handout. After five handover cycles, only 2.5 per cent of patient information was retained using the verbal-only handover, 85.5 per cent when using the verbal with note taking method and 99 per cent was retained when a printed handout was used (Bhabra et al., 2007). Another study within a critical care setting showed that more errors of distortion and omission arose during conventional handover compared with that supported by an electronic handover page (Pickering et al., 2009). Many others advocate the use of various frameworks and templates such as ISBAR (information, situation, background, recommendation), SOAP (subjective, objective, assessment, plan), and diNAMO (doctor, identity, needs, analysis, management, organisation). A cautionary note was though raised by one study (Alem et al., 2008) which found that supporting tools improved continuity in who was discussed but not in what was discussed at handover, resulting in a fragmented end picture. An analysis of both the technical and non-technical skills involved in handover suggested that it is not just the content that is important but also how the information is communicated (Pezzolesi et al., 2013). An integrated multi-disciplinary form of handover is thought to be a better model (Al-Benna et al., 2009; Zakrison et al., 2012). An Italian study suggested that patient participation in handover acts to "humanise relations" and increases patients' sense of safety (Wildner and Ferri, 2012).

Within a psychiatric setting one study highlighted a number of barriers to efficient clinical handover (Hunt et al., 2012). These included interruptions and insufficient time. Initiatives to improve handover including training have proven successful within psychiatry (O'Connor et al., 2011).

There are implications for education and training. Studies have suggested that new doctors feel unprepared for handover and there is a need to address this pre-qualification (Cleland et al., 2009; Kelly et al., 2011). The majority of participants in a psychiatric study (58 per cent) concurred there was a need for further training (Hunt et al., 2012). The handover toolbox (Drachsler et al., 2012) is the result of development of such an educational intervention, using innovative teaching technologies, aimed at supporting clinicians, trainers and educators by providing customised handover training tools for different clinical needs and contexts. The Handover Toolbox, in addition to advocating the use of tools and protocols also raises the importance of a supportive environment to allow the transfer of training into the workplace.

In 2009 The Australian Healthcare and Hospitals Association issued a paper entitled: "Clinical handover: system change, leadership and principles" in which it explores risks and developments in the field of handover and makes recommendations (AHHA, 2009). It convened a national multidisciplinary group to develop practical policy options around clinical handover and discusses the National Clinical Handover Initiative which aimed to identify, develop and improve handover in a range of healthcare settings.

The paper makes eight recommendations:

(1) A system with governance and leadership.

(2) National standards.

(3) Flexible standardisation - recognising the need to accommodate the realities within different wards, units and institutions.

(4) Clinical engagement and systemic cultural change. 
(5) The economic case - organised handover saves time and creates savings.

(6) Investment in technologies.

(7) Respect for workforce diversity.

(8) Rewards for success.

Trainee psychiatrist's handover

Due to lack of research within the field of psychiatry direct interpretation to our findings is limited. However, some important and useful principles do emerge. Almost universally a formalised process and guidelines are advocated. Errors may be reduced by improving training, use of supportive tools and a multidisciplinary approach.

This study reveals that within our own mental health trust handover practices varied considerably due to geography and nature of the clinical work. We tried to reflect this in the development of site specific SOP. It highlights a continued lack of awareness of formal handover processes as developed through the SOP. In addition, the results from the audits reveal that the SOP guidelines were not consistently adhered. We suspect that this information was drowned out in the rest of material issued during induction.

From 2008-2009 there was a discernible improvement in the handing over of information between on call doctors. However results for 2010 showed a subsequent deterioration. It is unclear what caused this deterioration. We postulate that the importance of handover faded over time.

We think that further refinement of the SOP and better dissemination of its existence would offer improved results. We do acknowledge that lack of awareness of policy is not an excuse enough and ultimate responsibility lies with the individual clinician with no room for complacency for patient safety (Singh et al., 2007).

Trainee comments indicated difficulties with uninterrupted time and limited access to supporting information systems. These need to be systematically addressed and further assessed.

In 2010 trainees were asked for the first time: "Are you aware of any incident when a patient's care has been put at risk because of inadequate handover?" It is worrying to see that a significant minority answered "yes" to this question. We need to bear in mind this may refer to one incident which has come to be known about by several of the trainees and does not imply that all those answering "yes" were directly involved. Perhaps a more useful question would be: "Are you aware of any incident when a patient's care has been put at risk because of inadequate handover in which you had direct involvement during your time on the current rota?" Subsequent audits might use such a question. However incidents when patient care has been placed at risk due to inadequate handover are taken extremely seriously. This is echoed in "An Organisation with a Memory" which finds that poor communication contributes to serious incidents and failures in the National Health Service (Department of Health, 2000).

This audit has some limitations. The results are drawn from a questionnaire designed specific to NTW Trust. Other national mental health trusts might have to devise their own handover procedures and audit tools. In addition, as with all audits, responder bias cannot be ruled out, with more motivated trainees completing the questionnaires, thereby potentially skewing results.

Subsequent to these audits there have been several changes to clinical practice at NTW Trust which has impacted the trainee's rotas. Rota Watch, an online "live" 
CGIJ

19,2

92

system accessible via the Trust's intranet, was commenced in January 2011. It provides the name and contact details of the on call doctors on every site. In addition, all first on call rotas within the trust are now resident. This facilitates face to face handover. The Trust has now implemented, RiO, an electronic database. Finally, a Trust wide handover working group has been designed with the aim of implementing guidelines and examining handover practices by all grades of doctors. We plan to work in future on developing a written handover process facilitated by IT infrastructure including laptops with 3G sim cards and blackberries. A future study might address handover processes subsequently.

\section{Declaration of interest}

None.

\section{Notes}

1. www.gmc-uk.org/NationalSurveyofTraineeDoctors2006.pdf_30531088.pdf

2. www.gmc-uk.org/guidance/good_medical_practice.asp

3. www.gmc-k.org/guidance/ethical_guidance/management_for_doctors.asp

4. www.gmc-uk/about/PMETB_archive.asp

5. www.schoolofpsychiatry.net/documents College Guidance 1.6

6. www.bma.org.uk/images/safehandover

7. www.nrls.npsa.nhs.uk/resources/clinical-specialty/mental-health

\section{References}

AHHA (2009), "Clinical handover - system change, leadership and principles", The Australian Healthcare and Hospitals Association, available at: http://ahha.asn.au/sites/default/files/ publication/11084/ClinicalHandover.pdf (accessed 18 October 2013).

Al-Benna, S., Al-Ajam, Y. and Alzoubaidi, D. (2009), "Burns surgery handover studies: trainees' assessment of current practice in the British Isles", Burns, Vol. 35 No. 4, pp. 509-512.

Alem, L., Joseph, M., Kethers, S., Steele, C. and Wilkinson, R. (2008), "Information environments for supporting consistent registar medical handover", Health Information Management Journal, Vol. 37 No. 1, pp. 9-24.

Bhabra, G., Mackeith, S., Monteiro, P. and Pothier, D.D. (2007), “An experimental comparison of handover methods", Annals of the Royal College of Surgeons of England, Vol. 89 No. 3, pp. 298-300.

Cleland, J.A., Ross, S. and Patey, R. (2009), “'There is a chain of Chinese whispers ...': empirical data support the call to formally teach handover to prequalification doctors", Quality and Safety in Health Care, Vol. 18 No. 4, pp. 267-271.

Department of Health (2000), An Organisation with a Memory, The Stationery Office, London.

Drachsler, H., Kicken, W., van der Klink, M., Stoyanov, S., Boshuizen, H.P.A. and Barach, P. (2012), "The handover toolbox: a knowledge exchange and training platform for improving patient care", BMJ Quality and Safety, Vol. 21 No. 1, pp. 114-120.

Hunt, G.E., Marsden, R. and O'Connor, N. (2012), "Clinical handover in acute psychiatric and community mental health settings", Journal of Psychiatric and Mental Health Nursing, Vol. 19 No. 4, pp. 310-318. 
Kelly, C., Noonan, C.L.F. and Monagle, J.P. (2011), "Preparedness for internship: a survey of new interns in a large Victorian health service", Australian Health Review, Vol. 35 No. 2, pp. 146-151.

Nasmyth, D.G., Pickersgill, A. and Hogarth, M. (1991), "Reducing hours of work of preregistration house officers: report on a shift system", British Medical Journal, Vol. 302 No. 6768, pp. 93-94.

O'Connor, N., Marsden, R., Ng, A., Parker, P. and Vella, N. (2011), "ISABAR? Is good! Implementing clinical handover in an area mental health service", Australian and New Zealand Journal of Psychiatry, Vol. 45, p. A47.

Pezzolesi, C., Manser, T., Schifano, F., Kostrzewski, A., Pickles, J., Harriet, N., Warren, I. and Dhillon, S. (2013), "Human factors in clinical handover: development and testing of a 'handover performance tool' for doctors' shift handovers”, International Journal for Quality in Health Care, Vol. 25 No. 1, pp. 58-65.

Pickering, B.W., Hurley, K. and Marsh, B. (2009), "Identification of patient information corruption in the intensive care unit: using a scoring tool to direct quality improvement in handover", Critical Care medicine, Vol. 37 No. 11, pp. 2905-2912.

Siemsen, I.M., Madsen, M.D., Pedersen, L.F., Michaelsen, L., Pedersen, A.V., Andersen, H.B. and Østergaard, D. (2012), "Factors that impact on the safety of patient handovers: an interview study", Scand J. Public Health, Vol. 40 No. 5, pp. 439-448.

Singh, H., Thomas, E.J., Petersen, L.A. and Studdert, D.M. (2007), "Medical errors involving trainees: a study of closed malpractice claims from 5 insurers", Arch Intern Med, Vol. 167 No. 19, pp. 2030-2036.

Wildner, J. and Ferri, P. (2012), "Patient participation in change-of-shift procedures: the implementation of the bedside handover for the improvement of nursing quality in an Italian hospice", Journal of Hospice and Palliative Nursing, Vol. 14 No. 3, pp. 216-224.

Zakrison, T., McFarlan, A., Namias, N., Stahl, K., Habib, F. and Nathens, A. (2012), "Understanding the handover of critically injured trauma patients - our nurses are our co-pilots", Critical Care Medicine, Vol. 40 No. 12, p. 178.

\begin{abstract}
About the authors
Dr Arun Gupta is a Consultant Psychiatrist for adults in Sunderland. He is a former Associate Director of Medical Education within NTW NHS Foundation trust. He also works as a medical teacher, trainer and supervisor. Professional interests include CBT, medical education, leadership and management. He has published in a variety of psychiatric subject areas. Dr Arun Gupta is the corresponding author and can be contacted at: ArunKumar.Gupta@ntw.nhs.uk

Dr Ruth Bevan is a Consultant Psychiatrist in intellectual disabilities working in NTW NHS Foundation trust. Areas of special interest are mental health in children and young people with intellectual disabilities and gender dysphoria. She has published in a peer reviewed journal.

Dr Akshya Vasudev is an Assistant Professor in the Department of Psychiatry at Western University, Canada. He completed his graduate training in medicine and post graduate training in pharmacology in India. Following this he undertook higher specialist training in old age psychiatry working in NTW NHS Foundation trust. His research interests are in neurobiology of late life depression and pharmacogenomics. He has published in a number of peer reviewed journals. He was awarded the Junior Investigator award by the International College of Geriatric Psychoneuropharmacology in 2009 for his contributions to research.
\end{abstract}

To purchase reprints of this article please e-mail: reprints@emeraldinsight.com Or visit our web site for further details: www.emeraldinsight.com/reprints 